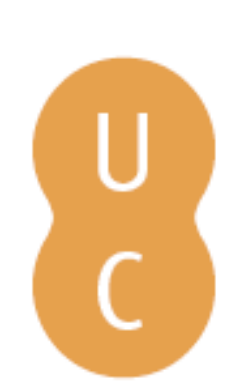

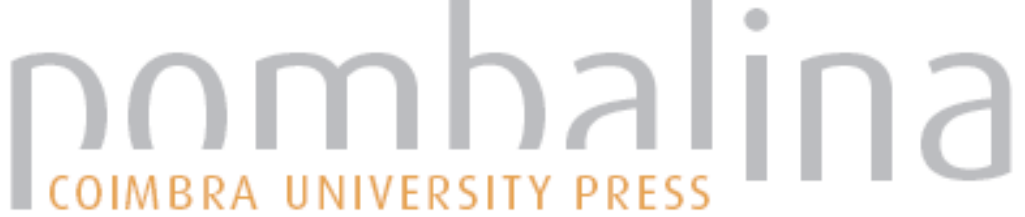

\section{Notas para uma leitura}

Autor(es): $\quad$ Prata, Manuel Alberto Carvalho, ed. lit.

Publicado por: Imprensa da Universidade de Coimbra

URL

persistente: URI:http://hdl.handle.net/10316.2/32276

DOI: $\quad$ DOI:http://dx.doi.org/10.14195/978-989-26-0425-1_3

Accessed : $\quad$ 26-Apr-2023 09:29:26

A navegação consulta e descarregamento dos títulos inseridos nas Bibliotecas Digitais UC Digitalis, UC Pombalina e UC Impactum, pressupõem a aceitação plena e sem reservas dos Termos e Condições de Uso destas Bibliotecas Digitais, disponíveis em https://digitalis.uc.pt/pt-pt/termos.

Conforme exposto nos referidos Termos e Condições de Uso, o descarregamento de títulos de acesso restrito requer uma licença válida de autorização devendo o utilizador aceder ao(s) documento(s) a partir de um endereço de IP da instituição detentora da supramencionada licença.

Ao utilizador é apenas permitido o descarregamento para uso pessoal, pelo que o emprego do(s) título(s) descarregado(s) para outro fim, designadamente comercial, carece de autorização do respetivo autor ou editor da obra.

Na medida em que todas as obras da UC Digitalis se encontram protegidas pelo Código do Direito de Autor e Direitos Conexos e demais legislação aplicável, toda a cópia, parcial ou total, deste documento, nos casos em que é legalmente admitida, deverá conter ou fazer-se acompanhar por este aviso.

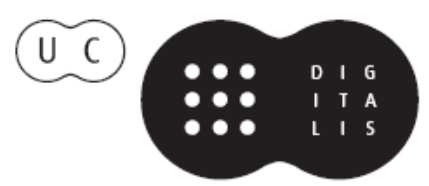


Manuel Alberto Carvalho Prata

Coordenação

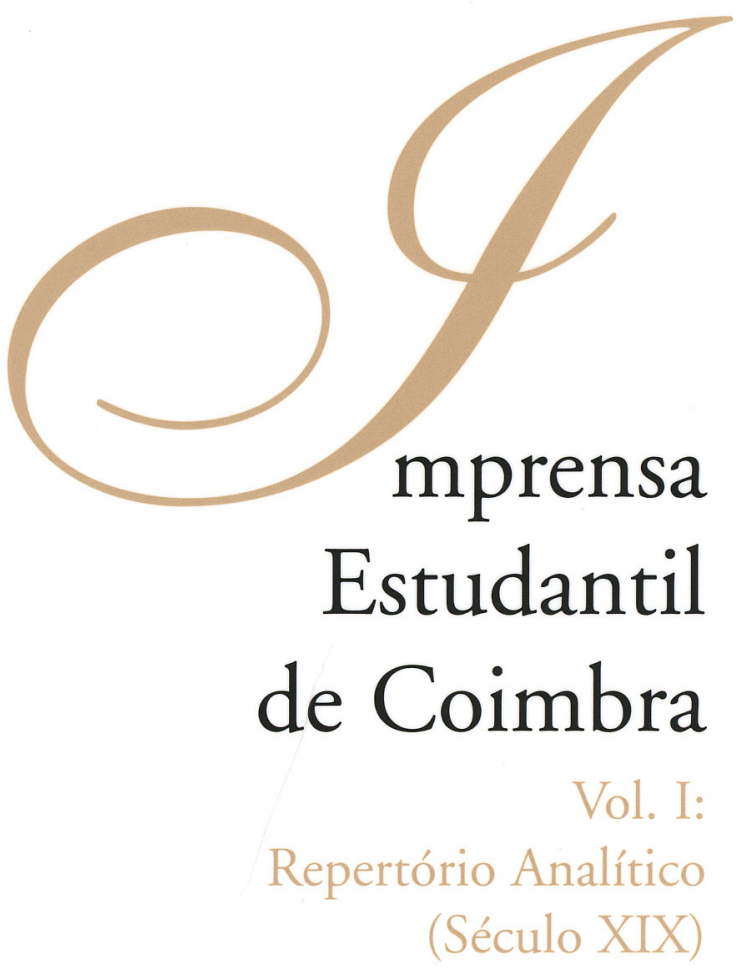

$\mathrm{Coimbra}$ - Imprensa da Universidade • 2006 


\section{NOTAS PARA UMA LEITURA}

Para cada publicação foi elaborada uma ficha de análise. Numeradas, cada ficha inclui: um cabeçalho, onde, de forma destacável, se inscrevem o respectivo número, o título do periódico, o subtítulo, quando existe, e outros elementos importantes na identificação da publicação.

Um pouco abaixo, seguem-se, depois, o nome dos responsáveis, os colaboradores e características técnicas do periódico. Separadamente, o objectivo e uma resenha de conteúdos.

Por motivos óbvios, num ou noutro caso, pode haver uma pequena referência bibliográfica.

Elaboraram-se, também, alguns índices: um índice cronológico, um temático e um onomástico. Naqueles remete-se para o número da ficha de análise; no onomástico, para as páginas.

Nos títulos e subtítulos, optámos por uma actualização da ortografia.

Periódicos houve que não conseguimos localizar, ou porque não existem nas bibliotecas, ou porque desapareceram simplesmente. Outros não passaram do prospecto. Apesar disso, incluímo-los, a todos, na nossa listagem, até por uma questão de informação.

\section{Cabeçalho}

No cabeçalho, apontam-se, numerados, os títulos e os subtítulos de cada periódico, bem como o local de edição e as datas de início e fim da publicação.

O título da publicação é apresentado em maiúsculas. Para marcar diferenças e evidenciar melhor os diversos tipos de periódicos, nos subtítulos optou-se por uma impressão em itálico.

Quando, por qualquer motivo, há mudanças nos títulos ou nos subtítulos, procura-se que aquelas sejam assinaladas em nota de rodapé. 
Aponta-se o local de edição. Acontece, por vezes, que um ou outro periódico muda de local de edição. Utilizando o mesmo critério, procura-se dar conta dessa alteração.

Sempre que possível, apresentam-se as datas, o mais completas possível, do início e terminus de cada publicação, quando existem.

Já fora do cabeçalho, e à sua direita, referem-se bibliotecas (Biblioteca Nacional, Biblioteca Geral da Universidade de Coimbra, Biblioteca Pública Municipal do Porto e Biblioteca Municipal de Coimbra) e apresentam-se as cotas de cada publicação, quando ainda existem.

\section{Responsáveis pela publicação}

Sempre que mencionados, indicam-se os responsáveis pela publicação: director, corpo redactorial, editor, proprietário e administrador.

Por vezes, estes responsáveis apresentam-se com pseudónimos. Embora não tivéssemos feito pesquisas para identificar pseudónimos, contudo, em alguns casos, foi possível fazer a respectiva identificação, da qual procuramos dar conta.

Dada a pouca longevidade que, normalmente, estas publicações apresentam, não se verificam grandes alterações nos corpos dirigentes. No entanto, sempre que alguma ocorra, procuramos, igualmente, assinalá-la.

\section{Colaboradores}

Apresentam-se, também, os colaboradores. Publicações há que, dado o elevado número de colaboradores, optámos por não referi-los todos, limitando-nos a apontar os principais. Com uma ou outra excepção, de um modo geral, não se identificam nem se referem as personalidades que assinam os seus artigos com pseudónimos ou usam, simplesmente, iniciais.

\section{Formato}

Medido em centímetros, fica-nos a impressão de nem sempre se apontarem as dimensões exactas. Deve-se este facto ao modo como algumas das publicações se apresentam, ao seu estado de conservação e à forma como foram aparadas, aquando da sua encadernação.

Dado o facto de, por vezes, se trabalhar com colecções incompletas, fica-nos, também, a sensação de, nesta matéria, as informações não terem a precisão 
desejada. Todavia, sempre que se detectam alterações no formato, procuramos dar conta delas.

\section{Periodicidade}

De um modo geral, a periodicidade que se indica é a que consta da própria publicação ou do prospecto que lhe serviu de anúncio. Isto não significa que a periodicidade referida tenha sido cumprida. É que a saída de qualquer publicação estudantil tem muito a ver com a disponibilidade financeira do seu director. Números de periódicos houve que não chegaram a ser distribuídos, apesar de prontos, por não se efectuar o pagamento à tipografia.

Publicações há, também, que, por motivos vários, dão à estampa, simultaneamente, mais que um número.

Quando a periodicidade não é referida, assinala-se com um simples - Não indica. Quando se trata de números únicos, evidencia-se o facto.

\section{Tiragem}

É um elemento que só muito raramente é indicado. Daí a sua não inclusão nas características da publicação. Todavia, sempre que referida, regista-se.

\section{Preço}

Regra geral, nas publicações aparecem dois preços: o de assinatura, que, normalmente, cobre um período de três meses e o preço avulso. São, fundamentalmente, estes os preços que registamos. Publicações há, também, que apresentam preços de séries. Outros indicam os preços para Coimbra e para a província.

\section{Páginas}

De uma maneira geral, o número de páginas tem muito a ver com o tipo de publicação. Se o periódico é um jornal, normalmente, a paginação é independente nos diferentes números.

Quando se trata de uma revista, acontece, muitas vezes, a numeração ser seguida, o que, por vezes, pode causar alguns embaraços, sobretudo quando as colecções não estão completas. Daí, também, a sensação da informação incom- 
pleta. Nem sempre os números de uma publicação têm todos o mesmo número de páginas. Separados por um traço de união (-), podem aparecer duas numerações, que correspondem ao número máximo e mínimo de páginas. Sempre que possível, registamos a alteração.

\section{Objectivo}

Normalmente, sempre que uma publicação se apresenta ao público, os seus responsáveis, em textos de maior ou menor dimensão, informam-nos sobre os seus propósitos e sobre o programa que têm em mente e procuram executar. Por isso, o objectivo da publicação é, na maior parte dos casos, composto por excertos, o mais esclarecedores possíveis, dessas notas programáticas de abertura e apresentação.

Casos há, no entanto, que, por este ou aquele motivo, aquela situação não se verifica ou porque o n. ${ }^{\circ} 1$ do periódico não se encontra, não chegou a publicação a efectuar-se, ou, então, porque os seus responsáveis se recusam a apresentar qualquer programa. Nestes casos, optámos, sempre que possível, por citar o texto inserido no prospecto de anúncio, quando existe, ou por seleccionar textos, colhidos em outros números, que nos pareceram mais esclarecedores sobre as intenções da publicação. É que é muito vulgar, passado algum tempo - três meses, um ano ou no fim de uma série -, fazer-se um balanço da actividade desenvolvida. Em qualquer dos casos, os excertos dos textos seleccionados estão sempre identificados.

Quando nada se escreve, é porque os seus responsáveis nada dizem ou, então, não se encontrou, realmente, nada digno de referência.

\section{Conteúdos}

Depois de uma apresentação genérica da publicação e de uma breve alusão à sua estrutura, procuramos referenciar as matérias abordadas. De algumas faz-se, inclusivamente, um desdobramento temático.

Para evidenciar melhor determinados pensamentos e linhas de força recorremos, várias vezes, à citação. 